\title{
DETERMINATION OF FORMATION REGIMES FOR BILAYER COBALT DYSPROSIUM INTERMETALIC SURFACE ALLOY
}

\author{
Vadym Kovalenko \\ Department of Analytical Chemistry and Chemical Technology of Food Additives and Cosmetics ${ }^{l}$ \\ Competence center "Ecological technologies and systems" \\ vadimchem@gmail.com \\ Denis Kondratyev \\ Department of Technology Inorganic Substances and Electrochemical Productions ${ }^{2}$ \\ denis512a@mail.ru \\ Valerii Kotok \\ Department of Processes, Apparatus and General Chemical Technology ${ }^{1}$ \\ Competence center "Ecological technologies and systems" \\ valeriykotok@gmail.com \\ Olga Chernova \\ Department of Technology Inorganic Substances and Electrochemical Productions ${ }^{2}$ \\ olgavc_kirov@mail.ru \\ Ihor Kovalenko \\ Department of Inorganic Chemistry ${ }^{l}$ \\ il.kovalenko050@gmail.com \\ Sergey Zhykovin \\ Department of Technology Inorganic Substances and Electrochemical Productions ${ }^{2}$ \\ zhykovin@mail.ru \\ Viktor Ved \\ Department of Equipment of Chemical Plants ${ }^{1}$ \\ 251277ved@gmail.com \\ Volodymyr Verbitskiy \\ National Ecology and Nature Center \\ 19 Vyshgorods'ka str., Kyiv, 04074, Ukraine \\ National Pedagogical Dragomanov University \\ 9 Pyrogova str., Kyiv, Ukraine, 01601 \\ vladimir.verbitskiy@gmail.com \\ ${ }^{1}$ Ukrainian State University of Chemical Technology \\ 8 Gagarina ave., Dnipro, Ukraine, 49005 \\ ${ }^{2}$ Vyatka State University \\ 36 Moskovskaya str., Kirov, Russian Federation, 610000
}

\footnotetext{
Abstract

High tech industrial fields on modern development stage are in need of construction materials with an optimal ratio of volume and surface properties, along with low cost of material itself. As evidenced by studies, in order to give a set complex of properties to a workpiece that operates under specific conditions, it is often sufficient to only modify its surface area. Over the course of studies, by means of gravimetric, influence of technological parameters (temperature and time samples are kept in the melt) on specific mass change of cobalt samples, that act as substrate, during electroless diffusive saturation with dysprosium in eutectic melt of lithium and
} 
potassium chlorides have been studied. A mathematical dependency was established for specific mass change of cobalt samples on time spent in melt for temperature range of 873-973 K. Composition of intermetallic coats obtained on surface of cobalt samples was studied means of EDX and SEM analyses. It was discovered, that for chosen temperature range, diffusion layers formed on surface of cobalt samples consists of two structural zones that correspond to Co-Dy and $\mathrm{Cp}_{2} \mathrm{Dy}$ phases.

Keywords: electroless transfer, dysprosium, diffusive saturation, surface alloy.

DOI: $10.21303 / 2461-4262.2019 .001011$

\section{Introduction}

Formation of intermetallic surface alloys provides unique characteristics to workpieces: improved resistance to high-temperature gas corrosion, highly effective magnetic properties [1-3]. There are many methods for forming intermetallic compounds (IMC) on surface of a workpiece, such as electrolysis in salt melt, plasma, and electric arc treatment. But, the least equipment demanding is electroless diffusion saturation in salt melt. It allows for surface modification of cobalt workpiece without electrical current, by forming intermetallic alloy within its surface at temperatures above $800 \mathrm{~K}$. Thickness and formation rate of this alloy can be controlled by process duration and temperature regime, with only additional requirement being creation of inert atmosphere (for instance, argon).

Electrochemical processes that occur in salt melts are studied rather well [4-7]. Paper [8,9] describes a study on the formation of IMC during electroless diffusive saturation. In present work, formation condition of Co-Dy IMC on surface of cobalt sample during electroless diffusive saturation in eutectoid mixture of lithium and potassium chlorides with addition of dysprosium chloride have been studied.

\section{Methods for studying the influence of regimes on kinetic characteristics of electroless diffu- sive Co-Dy alloy formation}

2. 1. Materials for studying the influence of regimes on kinetic characteristics of electroless diffusive Co-Dy alloy formation

Salt melt was prepared using analytical grade reagents, melt samples were prepared from cobalt and dysprosium of K-I and DiM-I grade. Dysprosium chloride was prepared from crystal hydrate, by heating it with excess of ammonium chloride under vacuum. Lithium chloride was dehydrated by remitting in glassy carbon crucible under vacuum. It was mixed with set amount of potassium chloride and malted in quartz cell, purged with dry hydrogen chloride till it cooled down and stored desiccator under argon. Diffusive saturation of cobalt sample in prepared eutectoid mixture was conducted according to method described in paper [10]. The experiment was conducted in stainless steel cell (Fig. 1) under argon atmosphere.

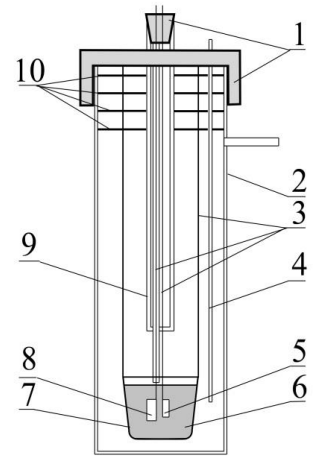

Fig. 1. Cell for studying diffusive saturation: 1 - rubber stoppers; 2 - stainless steel cell; 3 - molybdenum hinges; 4 - quartz thermocouple cover; 5 - studied sample, cobalt; 6 - electrolyte (melt); 7 - beryllium oxide crucible; 8 - rare-earth metal (dysprosium); 9 - quartz tube; 10 - aluminum shields 
Sample of the eutectoid mixture ( $30 \pm 2 \mathrm{~g}$ ) was placed into beryllium oxide crucible fixed on molybdenum hinge. The cell was sealed and heated under vacuum in an electric furnace to a set temperature. The temperature range was chosen according to data from preliminary tests, based on phase diagram for Co-Dy system. After reaching the temperature regime, cell was filled with argon and under its flow, samples of cobalt and dysprosium, fixed on molybdenum hinges, parallel to each other, were placed into the melt. Area of cobalt sample was $1.4 \pm 0.8 \mathrm{~cm}^{2}$, and dysprosium $-9 \pm 2 \mathrm{~cm}^{2}$. After set period of time, samples were removed from cell and cooled in desiccator under argon, washed in ethanol and weighted. Then, specific change in mass of cobalt sample was calculated, which was used to as qualitative characteristics of alloy formation on cobalt surface.

\section{2. Instruments for studying influences of regimes on kinetic characteristics of elec-} troless diffusive Co-Dy alloy formation

Structure of formed surface alloy was studied using the scanning electron microscope JEOL (Japan) with EDS module JSM-6510 LV (Japan), and its phase composition was studied using X-ray diffractometer XRD-7000 (Japan). This equipment proved itself for analysis of metallic systems. It allows for step-wise record of intermetallic compounds composition, component distribution of across coat volume, which is important for study on formation condition of coat composed of few structural zones.

\section{Results of studying influences of regimes on kinetic characteristics of electroless diffusive Co-Dy alloy formation}

Experimental results of determining the mathematical dependency of specific weight change of $(P)$ of cobalt samples on time in melt $(\tau)$, in studied temperature range are shown in Fig. 2. Obtained graph dependencies were processed using equation 1 :

$$
P=k_{m} \cdot \tau^{n}
$$

where $k_{m}$ - rate constant of diffusive saturation; $\tau$ - time of diffusive saturation; $n$ - exponent, the value of which can be used to judge limiting stage of the diffusive saturation process.

Value of relative error in conducted measurements of change in mass of cobalt samples was evaluated as $\Delta P / P_{\text {calc. }}(\%)$.

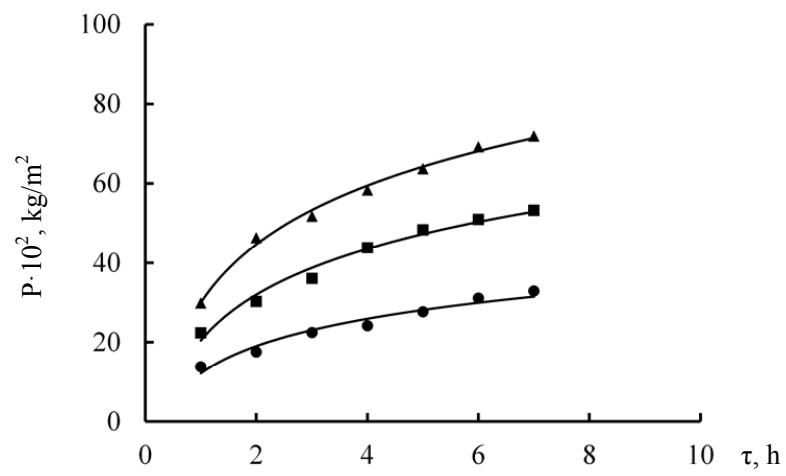

Fig. 2. The dependency of specific mass change in cobalt samples $(P)$ on time in the melt $(\tau)$ at temperatures: $1-873 ; 2-923 ; 3-973 \mathrm{~K}$

Table 1 shows the results of calculating rate constant of diffusive saturation and exponent $n$ for each studied temperatures. It also shows maximum values of relative error of conducted measurements.

Result of composition and structure studies of intermetallic alloy obtained on the surface of cobalt in eutectoid melt of lithium and potassium chlorides with addition of dysprosium under set conditions are shown in Table 2 and Fig. 3. 
Table 1

Calculated values of coefficient in equation (1)

\begin{tabular}{ccccc}
\hline $\mathbf{T}, \mathbf{K}$ & $\mathbf{k}_{\mathbf{m}}$ & $\mathbf{n}$ & $\Delta \mathbf{P} / \mathbf{P}_{\text {calc. }}, \mathbf{\%}$ & 3.5 \\
873 & 0.13 & 0.46 & 0.46 & 5.0 \\
923 & 0.22 & 0.45 & 3.6
\end{tabular}

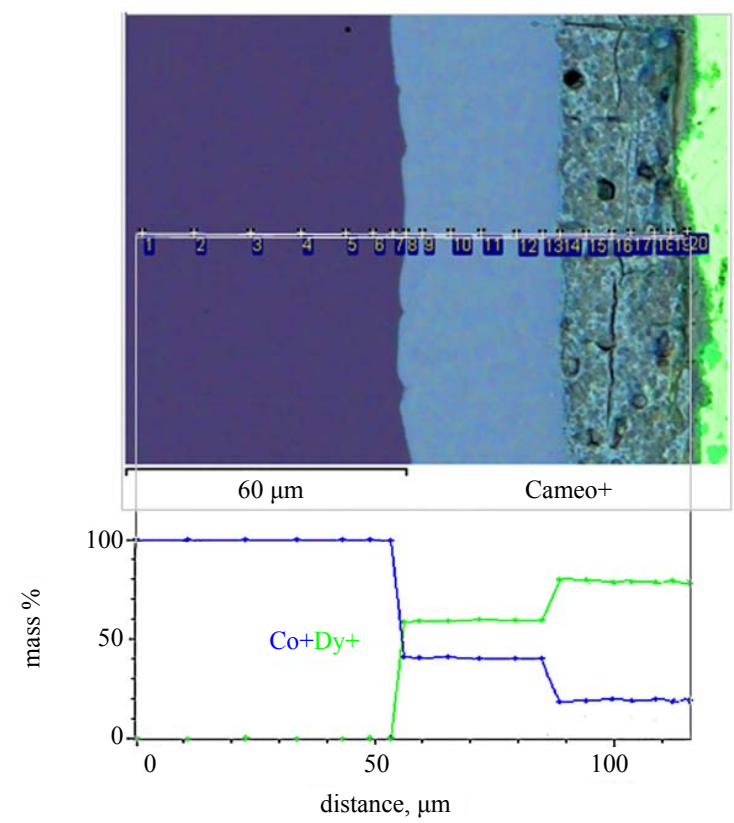

Fig. 3. Results of EDS analysis of Co-Dy surface alloy ( $\tau=6 \mathrm{~h}, T=973 \mathrm{~K}, P=0.69 \mathrm{~kg} / \mathrm{m}^{2}$ )

Table 2

Micro distribution of components across coat's thickness Co-Dy $\left(\tau=6 \mathrm{~h}, \mathrm{~T}=973 \mathrm{~K}, P=0.69 \mathrm{~kg} / \mathrm{m}^{2}\right)$

\begin{tabular}{cccc}
\hline \multirow{2}{*}{ Spectra (Fig. 3) } & \multicolumn{1}{c}{ Quantitative result, mass. \% } & Total \\
\cline { 2 - 4 } 1 & Co & Dy & 100.00 \\
2 & 100.00 & 0.00 & 100.00 \\
3 & 100.00 & 0.00 & 100.00 \\
4 & 100.00 & 0.00 & 100.00 \\
5 & 100.00 & 0.00 & 100.00 \\
6 & 100.00 & 0.00 & 100.00 \\
7 & 100.00 & 0.00 & 100.00 \\
8 & 100.00 & 0.00 & 100.00 \\
9 & 41.62 & 58.38 & 100.00 \\
10 & 41.08 & 58.92 & 100.00 \\
11 & 41.09 & 58.91 & 100.00 \\
12 & 40.37 & 59.63 & 100.00 \\
13 & 40.84 & 59.16 & 100.00 \\
14 & 40.84 & 59.16 & 100.00 \\
15 & 20.66 & 79.34 & 100.00 \\
16 & 21.25 & 78.75 & 100.00 \\
17 & 21.50 & 78.50 & 100.00 \\
18 & 21.18 & 78.82 & 100.00 \\
19 & 21.01 & 78.99 & 100.00 \\
20 & 20.78 & 79.22 & 100.00
\end{tabular}


Diffusion layers formed in this metallic system over the coerce of experiments are composed of two structural zones that correspond to Co-Dy and $\mathrm{Co}_{2}$-Dy phases. Existence of IMC, with discovered composition, in corresponding binary systems is also described in papers [11-13].

Over the course of studies, it was found that under experimental condition, the formation of intermetallic surface alloy with thickness from 10 to $100 \mu \mathrm{m}$ is possible. For instance, after six hours at $973 \mathrm{~K}$, coat of about $90 \mu \mathrm{m}$ can be formed on surface of cobalt, which enables development of technological control maps with for formation of surface alloys of required thickness.

\section{Discussion of results of studying influences of regimes on kinetic characteristics of electro- less diffusive Co-Dy alloy formation}

Based on the analysis of obtained graph dependencies, it can be concluded that higher temperature intensifies alloy formation due to higher diffusion rate in solid phase.

In equation (1), which describes the dependency of weight gain of saturation time, constant $k_{m}$ is a complex function which combines an array of factors, such as saturation temperature, nature of substrate and saturating element, which affects process rate. Calculate constant values for saturation of cobalt with dysprosium are similar to those previously obtained [14].

Results of calculating exponent $n$ (Table 1), show, that for all studied temperatures its value is close to 0.5 , in which case, based on result of work [15], it can be concluded that limiting stage of alloy formation for studied cases if diffusion in solid phase, meaning that electroless transfers under condition when mass transfer in salt medium is significantly higher than diffusion in solid phase, which is characteristic of alloy formation in Co-REM systems [14].

Results of the conducted analysis on obtained intermetallic cobalt-dysprosium coats showed that understudied condition formation of bilayer coat occurs, structural zone of which is richer in dysprosium on sample surface (Co-Dy), with lower content of REM closer to substrate metal $\left(\mathrm{Co}_{2}\right.$-Dy). This is in agreement with results of paper [14], which describes formation of bilayer intermetallic coats on surface of cobalt samples. When studying condition of preparing IMC Co-Pr alloys in chloride melts, it was found that at temperatures 725 and $775 \mathrm{~K}$, the formed coat consist of two phases: $\mathrm{Co}_{1.7} \mathrm{Pr}_{2}$ and $\mathrm{Co}_{2} \mathrm{Pr}$.

\section{Conclusions}

A series of experiments was conducted on formation of intermetallic surface alloy on the surface of cobalt substrate by electroless diffusive saturation it surfaces with dysprosium at temperature of 873,923 and $973 \mathrm{~K}$ in eutectoid salt melt $\mathrm{LiCl}-\mathrm{KCl}-\mathrm{DyCl}{ }_{3}$, for 1 to 7 hours.

Based on results of processing of obtained graph dependency of specific mass change of cobalt sample on time in melt, it was found that for all studied temperatures, formation rate is limited by slow diffusion rate of dysprosium in solid phase, which is in agreement with previous results obtained for Co-REM systems, such as with praseodymium.

Conducted EDX and SEM analyses of intermetallic coats on obtained on the surface of cobalt, revealed that understudied conditions a bilayer coat are formed, which consists of $\mathrm{Co}_{2} \mathrm{Dy}$ phase, closer to metal substrate, and CoDy on coat's surface.

\section{References}

[1] Kondrat'ev, D. A., Eremeeva, T. V., Kamalov, K. O., Kovalenko, V. L., Kotok, V. A., Kovalenko, I. L. (2019). Producing of surface alloys of the erbium-nickel system in halide melts. ARPN Journal of Engineering and Applied Sciences, 14 (1), 95-100.

[2] Verbetsky, V. N., Velikorodniy, Y. A., Lushchekina, S. V. (2002). Synthesis of hydride based on the intermetallic compound $\mathrm{YbNi}_{2}$. Bulletin of the Moscow-Univ. Series 2: "Chemistry", 1 (43), 58.

[3] Xiao, Z., Geng, H., Sun, C., Jia, P., Luo, H. (2015). Effect of yttrium on properties of copper prepared by powder metallurgy. Advanced Powder Technology, 26 (4), 1079-1086. doi: https://doi.org/10.1016/j.apt.2015.05.003

[4] Kushkhov, K. B., Vindizheva, M. K., Mukozheva, R. A., Tlenkopachev, M. R., Abazova, A. K. (2013). Electroreduction of cerium(III) ions on a silver electrode in a chloride melt at $823 \mathrm{~K}$. Russian Journal of Electrochemistry, 49 (4), $365-368$. doi: https://doi.org/10.1134/s1023193513040125 
[5] Bushuev, A. N., El'kin, O. V., Tolstobrov, I. V., Sazanov, A. V., Kondrat'ev, D. A. (2018). Preparation of a Nickel-Holmium Alloy Coating in an Equimolar HoCl3-Containing NaCl-KCl Melt. Russian Metallurgy (Metally), 2018 (8), $771-776$. doi: https://doi.org/10.1134/s0036029518080049

[6] Novoselova, A. V., Smolenskii, V. V. (2013). Electrochemical and thermodynamic properties of lanthanides (Nd, Sm, Eu, Tm, $\mathrm{Yb}$ ) in Alkali metal chloride melts. Radiochemistry, 55 (3), 243-256. doi: https://doi.org/10.1134/s1066362213030016

[7] Novoselova, A. V., Smolenskii, V. V. (2012). Electrochemical study of the reduction of Tm(III) ions in a molten $\mathrm{NaCl}-2 \mathrm{CsCl}$ eutectic. Russian Journal of Applied Chemistry, 85 (2), 218-224. doi: https://doi.org/10.1134/s1070427212020097

[8] Ilyushchenko, N. G., Anfinogenov, A. I., Shurov, N. I. (1991). Interaction of metals in ionic melts. Moscow: Nauka. 1991.

[9] Kondratyev, D. A., Kovalevsky, A. V., Chebykin, V. V. (2013). Alloy formation during the current-free diffusion saturation of nickel with dysprosium in the melt of LiCl-KCl-DyCl. Melts, 6, 47-52.

[10] Elkin, O. V., Chebykin, V. V., Kovalevsky, A. V. (2009). The kinetics of the alloying-tion when currentless transfer of ytterbium, samarium and gadolinium nickel in chloride melts. Melts, 4, 20-26.

[11] Gshneyder, K. A. (1965). Alloys of rare earth metals. Moscow: Mir.

[12] Gladyshevsky, E. I., Bodak, O. I. (1982). Crystal chemistry of nonmetallic compounds of rare-earth metals. Lviv: High school.

[13] Buschow, K. H. (1971). Rare-Earth-Cobalt Intermetallic Compounds. Philips Res. Repts., 26, $49-64$.

[14] Kovalevsky, A. V., Soroka, V. V. (1986). Diffusion saturation of cobalt with rare-earth metals in chloride melts. Improving the technology of galvanic coatings. Kirov, 39-40.

[15] Baraboshkin, A. N. (1986). On conditions for a smooth diffusion coatings are dead and electrodeposition transfer. Temperature Electrochemistry. Sverdlovsk, 36-41. 